were found in $14.6 \%, 10.5 \%, 10.2 \%, 0.3 \%$ and $0.5 \%$ respectively. Smoking was found in only 10 patients $(2.7 \%)$

Conclusions: : The prevalence of PsA in Egyptian patients with psoriasis appears to be within the range reported in other studies. Whereas, most of PsA onset was found to precede the psoriasis.

Disclosure of Interest: None declared

DOI: 10.1136/annrheumdis-2018-eular.7571

\section{AB1284 PRELIMINARY DATA OF VACCINATION STATUS, POST VACCINATION IMMUNITY AND LATENT TUBERCULOSIS IN PATIENTS WITH CHRONIC INFLAMMATORY DISEASE IN A RHEUMATOLOGY CONSULTATION IN ST RAFAEL'S HOSPITAL IN BARCELONA}

A. Erra ${ }^{1}$, H. Borrell ${ }^{1}$, L. López ${ }^{1}$, X. Martinez ${ }^{2} .{ }^{1}$ Rheumatology, Hospital San Rafael; ${ }^{2}$ Preventive medicine, Hosptial Vall Hebron, Barcelona, Spain

Background: Chronic inflammatory diseases (CID)(Rheumatoid arthritis(RA), Psoriatic arthritis(PsA) and ankylosing spondylitis(AS) are treated with disease modifying antirheumatic drugs(DMARDs). The most common adverse events are infections so an adequate vaccination is necessary before starting these treatments

Objectives: Determine the vaccination status, post-vaccination response and presence of latent tuberculosis(TB) in patients(pts)with CID

Methods: Before treatment with DMARDs, hepatitis $\mathrm{C}$ virus(HCV) antibodies, hepatitis $\mathrm{B}(\mathrm{HBV})$ surface antigen are determined. Following the guideline of Spanish Society of Rheumatology, before start a biological treatment(BT), latent tuberculosis(TB)screening is done by PPD and booster test. We and Preventive Medicine Department(PMD) of Vall Hebron Hospital(VHH) stablished vaccination protocol for pts with CID treated with DMARDs or/and BT:anti pneumococcal vaccination, virus serological status(varicella zoster $\lg G$, measles $\lg G$, anti-hepatitis A IgG, HBV surface antigen, HBV anti-surface antigen, HBV anti-core antigen and anti-HCV) and quantiferon(QT) test by assessment latent TB. Vaccines were administered depending on the above tests such as the determination of the postvaccination HBV serology. Positive QT pts were referred to Infectious Diseases Department of $\mathrm{VHH}$ and received Isoniazid for 6 months

Results: From October 2016 to November 2017,123 pts with CID(including new onset and chronic disease) were referred to PMD. The pts were classified:81 RA (16 BT/65 DMARDs);25 PsA(9 BT/16 DMARDs),13 AS(10 BT/3 DMARDs),5 others(2 BT/3 DMARDS):2 juvenile idiopathic arthritis, 1 reactive arthritis, 1 monoarthritis and 1 polymyalgia rheumatica. Pts with BT were treated:14 RA with combined therapy(CT) and 2 with monotherapy;9 AS with monotherapy and 1 with CT,2 PsA with monotherapy and 7 with CT.19 pts had QT(+):2 had previously $\operatorname{PPD}(-) ; 3$ had previously $\operatorname{PPD}(+)$ and it was unknown in 14. Pts with $\operatorname{PPD}(+)$ and QT $(+)(n=4)$, all of them who received $B T(n=3)$ had been treated with isoniazid. The patient treated with DMARDs didn't received it. Pts QT(+) and previous PPD()$(n=2): 1$ with BT for years and never before had been treated with isoniazid, so this treatment was started. The other with DMARDs started treatment with isoniazid as she was going to start BT in a short time. The rest of the pts QT $(+)(n=14)$ didn't have a previous PPD(all DMARDs).11 received prophylaxis with isoniazid and 3 didn't, because they didn't require BT soon.19\% of pts had positive HBV's serology, so they didn't receive HBV vaccination. $81 \%(n=100)$ had a negative anti-Ag surface HBV.92\% of them received the vaccination, and from them, $9 \%$ didn't develop immunologic response so they needed revaccination(3 received TC BT-DMARDs and 5 DMARDs in monotherapy).42\% developed immunologic response and in $49 \%$ we are waiting for the results. $16 \%$ had a negative HAV's serology and all of them received the vaccination

Conclusions: The quantiferon can detect latent TB in patients with negative PPD and booster. Most patients need vaccination to HBV. Check the immunity from $\mathrm{HBV}$ is necessary after vaccination to know if they need revaccination. In our preliminary data we have observed absence of immunity to HBV in patients who are treated with BT (with $\mathrm{CT}$ ) and also in patients who are treated with synthetic DMARDs.

Disclosure of Interest: None declared

DOI: 10.1136/annrheumdis-2018-eular.4406

\section{AB1285 2 SERUM INTERLEUKIN 33, A POSSIBLE NEW MARKER PREDICTING THE DEVELOPMENT OF VASCULITIS IN PATIENTS WITH SYSTEMIC LUPUS ERYTHEMATOSUS}

A. A.-R. Youssef ${ }^{1 *}$, A.E.M. A. Afify ${ }^{1}$, T.O. El-Said ${ }^{1}$, S.S. Metwaiiy ${ }^{2}$, D.M. Abd E Ghafar ${ }^{1} .{ }^{1}$ Rheumatology and Rehabilitation; ${ }^{2}$ Clinical Pathology, Mansoura University, Mansoura, Egypt

Background: Systemic lupus erythematosus (SLE) is an autoimmune disease characterised by abnormal production of autoantibodies and proinflammatory cytokines. Although interleukin-33 (IL-33), a novel member of the IL-1 family, has been reported to have proinflammatory effects, the association of IL-33 with SLE has not been fully investigated ${ }^{1}$

Objectives: To estimate serum levels of IL- 33 in Egyptian patients with SLE and in controls, and to find out any relation between IL-33 serum levels in SLE patients and disease activity in addition to other clinical and laboratory criteria.

Methods: 60 SLE Egyptian patients (53 females and 7males) diagnosed according to systemic lupus international collaborating clinics (SLICC); new classification criteria 2012 and 20 healthy controls matched for age and sex were included. Patients with diseases suggesting the possibility of increased serum IL-33 were excluded $^{2} 27$ SLE patients were diagnosed clinically as having vasculitis and this was confirmed by laboratory and imaging studies. Serum IL-33 was measured by sandwich ELISA Kit. Disease activity was assessed using SLE disease activity index (SLEDAI) score. ${ }^{3}$

Results: Using Mann-Whitney U test, median serum level of IL-33 (30.3 pg./ml) was significantly higher in patients with SLE than that of healthy controls $(24.80$ $\mathrm{p}=0.003)$. Using logistic regression analysis, SLE patients with high IL-33 serum levels have 3.8 times higher risk of developing vasculitis (OR 3.8 (1.1-13.6 $95 \% \mathrm{Cl}: \mathrm{p}=0.01$ ) and 3.2 times higher risk of developing oral ulcers (OR 0.3 .2 $(1.2-11.7,95 \% \mathrm{Cl}: \mathrm{p}=0.033$.) than those with lower IL-33 serum Levels. No significant correlation was found between serum levels of IL-33 and total SLEDAI score or any of the other clinical or laboratory criteria.

Conclusions: Our findings suggest that IL-33 may be considered as a possible new inflammatory marker predicting the development of vasculitis and/or mucosa ulcers in SLE patients. Neutralisation of IL-33 may hopefully result in a new therapeutic option for these patients. Further studies are warranted to get more conclusive results.

\section{REFERENCES}

[1] Yang, Z., Laing Y., Xi, W., Li, C., \& Zhong. R. Association of increased serum IL-33 Levels with clinical and laboratory characteristics of systemic lupus erythematosus in Chinese population. Clinical and Experimental Medicine 2011;11(2):75-80.

[2] Liew FY, Pitman NI, McInnes IB. Disease-associated functions of IL-33: the new kid in the IL-1 family. Nature Reviews Immunology 2010;10 (2):103-10

[3] Bombardier C, Gladman DD, Urowitz MB, Caron D, Chang CH, Austin A Decker J. L Derivation of the SLEDAI. A disease activity index for lupus patients. Arthritis \& Rheumatology. 1992, 35(6), 630-640.

Acknowledgements: We acknowledge the efforts received by all staff members of departments of Rheumatology and clinical pathology at Mansoura University Hospital, Egypt.

Disclosure of Interest: None declared

DOI: 10.1136/annrheumdis-2018-eular.2595

\section{AB1286 ANKYLOSING SPONDYLITIS (AS), PSORIATIC ARTHRITIS, UNDIFFERENTIATED (U) SPONDYLOARTHRITIS (SPA) IN INDIA: RESULTS FROM WHO ILAR COPCORD INDIA PROGRAM STAGE I SURVEY 2000-2010}

A. Chopra ${ }^{1}$, R. Ghorpade ${ }^{1}$, M. Saluja ${ }^{1}$, A. Venugopalan ${ }^{1}$, S. Sarmukaddam ${ }^{1}$, T. Kainifard ${ }^{2}$, K.M. Mahendranath ${ }^{3}$, on behalf of BJD- COPCORD Team India. ${ }^{1}$ rheumatology, Center for Rheumatic Diseases, Pune, India; ${ }^{2}$ rheumatology reserach, Tehran Univ of Medical Sciences, Teheran, Iran, Islamic Republic of Ireland; ${ }^{3}$ rheumatology, Arthritis Center, Bangalore, India

Background: Using a low cost low infrastructure model, the WHO ILAR COP. CORD (Community Oriented Program for Control of Rheumatic Diseases) surveys have covered several population in Asia and Latin America. The reported prevalence of AS based on large sample surveys was $0.2-0.3$ in China and 0.12 in Iran. We used the Bhigwan COPCORD model to complete comprehensive surveys at several urban and rural site in India.

Objectives: To describe the prevalence of $\mathrm{SpA}$ in India with a focus on AS

Results: 51741 population (66\% rural) in 11 sites all over India was screened using a suitable COPCORD core questionnaire and protocol. Stage I survey was carried out in 3 concurrent overlap phases. House to house visit identified respondents with current/past musculoskeletal pain (last 7 days). Paramedics interviewed respondents to map MSK pain and record patient centric outcome including an Indian version HAQ (Phase 2). Clinical evaluation was carried out by rheumatologists with minimal investigations (Phase 3 ). The diagnosis was clinical. Survey sites and samples were chosen by convenience. Data was centrally processed and analysed using standard software; significant $p<0.05$. Data standardised (age-gender) as per; India census 2002 adjusted prevalence reported. 
Abstract AB1286 - Table 1

\begin{tabular}{lccc}
\hline Disorder & $\begin{array}{c}\text { Male } \\
(\%)\end{array}$ & $\begin{array}{c}\text { Mean age (Range) } \\
\text { years }\end{array}$ & $\begin{array}{c}\text { Prevalence (95\% confidence } \\
\text { interval) }\end{array}$ \\
\hline $\begin{array}{l}\text { Spondyloarthritis } \\
\text { Ankylosing }\end{array}$ & 44.8 & $43(19-80)$ & $0.24(0.20-0.29)$ \\
Spondylitis & 72.2 & $39(19-65)$ & $0.03(0.02-0.06)$ \\
Psoriatic Arthritis & 64 & $54(40-80)$ & $0.02(0.00-0.03)$ \\
Undifferentiated & 38.4 & $42(21-80)$ & $0.19(0.16-0.23)$ \\
SpA & & &
\end{tabular}

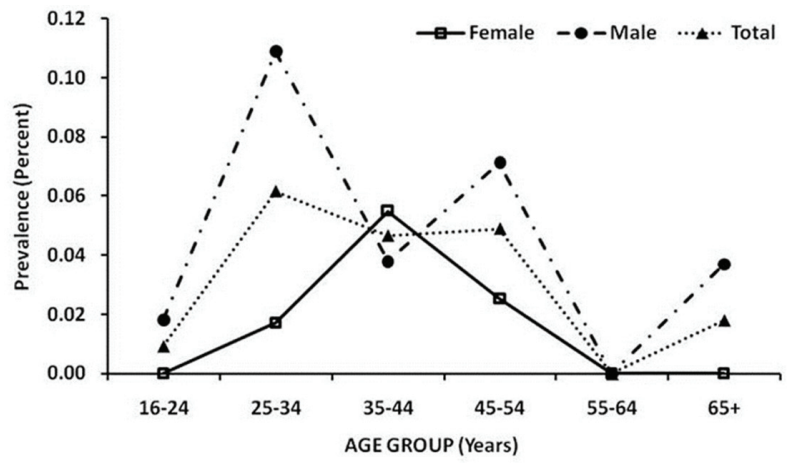

Abstract AB1286 - Figure 1

Conclusions: The burden of SpA in India (1.2 billion population) is enormous. Compared to global statistics, the prevalence of clinical AS and psoriatic arthritis in the Indian population appears low.

\section{REFERENCES:}

[1] www.copcord.org

[2] Chopra \& Nasser. (MSK Burden in Developing World). Best Pract Res Clin Rheumatol 2008;22(4):583-604

[3] Joshi \& Chopra (Bhigwan COPCORD model) J Rheumatol 2009;36:61422.

Acknowledgements: The Bone and Joint Decade India, collegue rheumatologists from academia and practise, support staff at COPCORD centres and community

Disclosure of Interest: None declared

DOI: 10.1136/annrheumdis-2018-eular.5006

\section{AB1287 A POPULATION-BASED STUDY ON THE PREVALENCE AND INCIDENCE OF VASCULAR PRIMARY ANTIPHOSPHOLIPID SYNDROME: A NEW RARE DISEASE}

C. Nalli ${ }^{1}$, L. Andreoli ${ }^{2}$, G. Pascariello ${ }^{1}$, A. Zentilin ${ }^{1}$, E. Raffetti ${ }^{3}$, G. Martini ${ }^{4}$, R. Kumar ${ }^{2}$, C. Gasparotti ${ }^{5}$, M. Magoni $^{5}$, C. Scarcella ${ }^{5}$, F. Donato ${ }^{3}$, A. Tincani ${ }^{2}$. ${ }^{1}$ Rheumatology and Immunology Unit, Department of clinical and experimental sciences, ASST Spedali Civili of Brescia; ${ }^{2}$ Rheumatology and Immunology Unit, Department of clinical and experimental sciences, Spedali Civili and University of Brescia; ${ }^{3}$ Unit of Hygiene, University of Brescia; ${ }^{4}$ Department of Diagnostics, Spedali Civili; ${ }^{5}$ Brescia Health Protection Agency, Brescia, Italy

Background: Antiphospholipid Syndrome (APS) is a systemic autoimmune disease characterised by the presence of thrombotic and/or obstetrical manifestations and antiphospholipid antibodies (aPL). In 2006 the updated Sapporo criteria for APS were published but by now no epidemiological study on this disease were performed. Incidence and prevalence of primary APS (PAPS) in the general population are still unknown.

Objectives: The aim of this study was to evaluate the prevalence during the year 2013 and incidence for the period 2011-2015 of vascular PAPS in the adult population of a defined area, Valtrompia valley, using multiple sources. Valtrompia is a 40 kilometers-long prealpine valley in northern Italy. The population in 2013 was 101.477 inhabitants. The only easy access to the valley is from Brescia, the main city of the province. This valley is a cul-de-sac area without any other comfortable and practicable access. Therefore, this valley is ideal for epidemiological studies. In addition, the only Rheumatology referral tertiary Centre of the province is located in Brescia. This project was approved by the local Ethical Committee.

Methods: We identified adult subjects of 18-50 years old living in Valtrompia. Patients with thrombotic events were identified by two sources: 1) hospital discharge code using keywords (deep vein thrombosis, pulmonary embolism, myocardial infarction, ischaemic stroke); 2) patients with defined diagnosis of vascular PAPS already followed by the Rheumatology tertiary Centre in Brescia.

Results: The prevalence of PAPS in 2013 was calculated to be 35.4 (Cl 95\% 20.6-59.6) per 100.000 inhabitants. Table 1 shows the incidence rates of vascular PAPS. We identified 47 patients with venous events during 2011-2015. 27/47 (57\%) were tested for aPL, 4/27 (15\%) positive. Regarding arterial events, 36 patients had stroke and 33/36 (92\%) were tested for aPL, 4/33 (12\%) positive. Finally, 64 patients with myocardial infarction (IMA): only 14/64 (22\%) were tested for aPL, 2/14 (14\%) positive.

Table 1 Incidence rates of antiphospholipid antibody syndrome per 100.000 inhabitants in Valtrompia in adult population (18-49 years) between 2011 and 2015. The $95 \%$ confidence intervals (Cls) are reported in parenthesis.

\begin{tabular}{|l|c|c|}
\hline & \multicolumn{2}{|c|}{ INCIDENCE } \\
\hline & Number of cases & $\begin{array}{c}\text { Incidence } \mathbf{9 5 \%} \text { CI) } \\
\text { per 100,000 }\end{array}$ \\
\hline OVERALL & & $3.7(1.7-7.1)$ \\
\hline Males + Females & 9 & $4.0(1.3-9.4)$ \\
\hline Males & 5 & $3.4(0.9-8.8)$ \\
\hline Females & 4 & \\
\hline & & $1.7(0.5-4.3)$ \\
\hline VENOUS THROMBOSIS & & $0.8(0.0-4.5)$ \\
\hline Males + Females & 4 & $2.6(0.5-7.5)$ \\
\hline Males & 1 & \\
\hline Females & 3 & $1.7(0.5-4.3)$ \\
\hline & & $2.4(0.5-7.1)$ \\
\hline STROKE/ICTUS & 4 & $0.9(0.0-4.8)$ \\
\hline Males + Females & 3 & \\
\hline Males & 1 & \\
\hline Females & & $0.4(0.0-2.3)$ \\
\hline & & $0.8(0.0-4.5)$ \\
\hline IMA & 1 & - \\
\hline Males + Females & 1 & \\
\hline Males & 0 & \\
\hline Females & & \\
\hline & & \\
\hline & & \\
\hline & & \\
\hline & & \\
\hline & & \\
\hline & & \\
\hline & & \\
\hline & & \\
\hline & & \\
\hline & & \\
\hline & & \\
\hline & & \\
\hline
\end{tabular}

Abstract AB1287 - Figure 1

Conclusions: Preliminary results of this population-based study showed that PAPS is a rare disease. A critical point emerged from this study is that aPL were not routinely tested in young subjects with vascular events, especially in patients with myocardial infarction. The study will be implemented by contacting patients who never tested for aPL during the hospital admission.

Disclosure of Interest: None declared

DOI: 10.1136/annrheumdis-2018-eular.5676

\section{AB1288 2 PREDICTION OF AMENORRHEA IN FEMALE RHEUMATOID ARTHRITIS PATIENTS WITH TRIPTERYGIUM WILFORDII HOOK F}

C. Zhang ${ }^{1}$, Y. Xu ${ }^{2}$, M. Liu ${ }^{3}$, X. He ${ }^{1}$, C. Lu ${ }^{1}$, A. Lu ${ }^{4} .{ }^{1}$ Institute of Basic Research in Clinical Medicine, China Academy of Chinese Medical Sciences, Beijing;

${ }^{2}$ Department of Traditional Chinese Medicine; ${ }^{3}$ Department of Gynecology, The Third Affiliated Hospital of Guangzhou Medical University, Guangzhou; ${ }^{4}$ School of Chinese Medicine, Hong Kong Baptist University, Hongkong, China

Background: : The Chinese anti-inflammatory and immunosuppressive herbal remedy Tripterygium wilfordii Hook $F(T w H F)$ is a widely used and effective treatment for rheumatoid arthritis (RA). Ovarian failure is one of the most importan adverse effects among pre-menopausal women with TwHF therapy.

Objectives: To construct a statistical model for pre-treatment prediction of amenorrhea after TwHF therapy.

Methods: In this retrospective study, potential predictors of amenorrhea including demographic and clinical data were retrieved. Multivariate logistic regression models were used to evaluate the association between pre-treatment variables and amenorrhea. The probability of amenorrhea was calculated for combinations of pre-treatment variables.

Results: Post-TwHF therapy amenorrhea rate was $10.9 \%$ (70 of 641$)$. The mean age was $36.2 \pm 5.5$ years, mean body mass index $22.5 \pm 7.5 \mathrm{~kg} / \mathrm{m} 2$. Age was the 